\title{
Faculty Development Centers in Research Universities: A Study of Resources and Programs
}

\section{Delivee L. Wright}

University of Nebraska, Lincoln

The purpose of this study was to compile updated information on resources and programs of faculty/instructional development centers in Carnegie classification Research I and Research II universities. It allowes centers across the country to see where they stand in regard to a number of specific aspects of center operation. Size of institution, mission, resources, budgets, and staffing vary greatly, while activities and services have a greater degree of similarity. The data reveal a number of questions for further study and discussion.

\section{INTRODUCTION}

$\mathrm{F}^{\text {ach time directors of faculty/instructional development centers are }}$ Easked how their program compares to what other universities are doing, they must respond on the basis of estimates from personal contacts, or perhaps quick communication with other directors to get some information to share with those who make decisions about the future. The need for data that are representative of the resources and programs such centers provide prompted this survey.

Faculty development literature has only a few studies describing the kinds of resources and services that are characteristic of the field. Centra (1976) reported survey results of faculty development practices in US colleges and universities. Erickson (1986) replicated that study with a survey of 1,588 four-year institutions, concluding that "probably half or more ... offer some formal faculty development, instructional development, and/or teaching improvement services." A survey by Gullatt and Weaver 
(1997) studied faculty development activities used in 116 institutions. After identifying the topics covered, they concluded that centers were in existence and able to offer the greatest number of faculty development activities at campuses with larger institutional operating budgets. Chambers (1998) reported results of a survey of 1,350 two-year and four-year institutions finding similarity of services regardless of size or mission of the institution. He concluded that professional support is a need in higher education.

This study responds to the need to examine the resources and programs of faculty/instructional development centers in US research universities and to compile information into a single source that would allow centers in research universities across the country to see where they stand in regard to a number of specific aspects related to center administration. Crawley (1995) surveyed research universities to study their senior faculty renewal programs, but a broader examination of these centers has not been done.

\section{Procedures}

In the fall of 1997, senior academic officers at 125 Carnegie classification Research I and Research II universities were sent letters requesting center director's names. Fifty-five centers were identified and each was invited to participate in this study; thirty-three completed the survey $(60 \%$ response rate; see Appendix 1 for a list of institutions). The survey instrument was reviewed by 10 directors of centers in October 1997, and the surveys were revised and mailed in November 1997, followed by an additional mailing. Results are reported in raw numbers and percentages for the total of 33 responding campuses.

\section{Results}

The size of the audiences served by these centers varied greatly. Figure 17.1 represents the range and mode for faculty, part-time faculty, graduate teaching assistants, and international graduate teaching assistants. It also provides estimates of undergraduate and graduate student numbers.

\section{Line of Report and Funding}

Considerable commonality exists in the lines of reporting and funding sources, with $27(81.8 \%)$ centers reporting to the senior academic offices 
FiguRE 17.1

Estimates of Raw Numbers of Various Population Sizes on Responding Campuses

\begin{tabular}{lcr}
\hline Group & Range & Mode \\
\hline Full-time faculty & $413-3,500$ & 750 \\
Part-time faculty & $11-2500$ & 200 \\
Graduate teaching assistants & $150-3,000$ & 197 \\
International teaching assistants & $50-800$ & 200 \\
Undergraduate students & $6,000-42,000$ & 17,000 \\
Graduate students & $700-15,000$ & 7,000 \\
\hline
\end{tabular}

of the institution. Other lines of report included deans, university librarians, associate deans, or directors. In two cases, report is both to the senior academic office and to a dean.

All centers receive general funds, instructional funds, or administrative funds, and 21 centers $(63.6 \%)$ are entirely funded from one of these sources. The other $12(36.4 \%)$ reported additional funding from external revenues (5); grants or contracts (4); student fees (3); endowment or gifts (5); or earned income (1).

\section{Center Directors}

The administrative officers of 27 centers $(81.8 \%)$ are designated as a directors; for 3 others, the title of director is combined with associate provost, associate dean of undergraduate studies, or associate vice-provost; 1 reported the title of assistant vice-chancellor; 1 was a coordinator; and 1 center had co-directors. These leaders have served in their roles for a range of $0-16+$ years, with $15(45.5 \%)$ having served for 5 or fewer years and $16(48.5 \%)$ for over 5 years.

Twelve directors $(36.4 \%)$ were tenured faculty members at the same institutions before becoming center directors. A number of directors ( 8 or $24.2 \%$ ) reported previous positions on the staff of the same center or were untenured faculty from the same institution ( 4 or $12.1 \%$ ). Typically the director was promoted from "the inside" ( 27 or $81.8 \%$ ), with only 3 (9.1\%) reporting that they came from a different institution. Other prior positions included $1(3 \%)$ each as a faculty developer at this institution but different school, a teacher abroad, and a full-time graduate student (1 did not respond).

Respondents did not always answer the question on whether salaries 
represented an academic (nine month) or fiscal (twelve month) appointment, so it is difficult to know how this omission affects the salary data. Twenty-two directors indicated fiscal-year appointments, and four indicated academic-year appointments. Of the latter, two directors were also on half-time appointments in their academic departments. One center has three co-directors who were on quarter-time appointments with three-quarter time as departmental faculty. Other variables including the cost of living, tenure-status, and years of experience need to be considered in salary data. See Figure 17.2 for salary levels reported for directors.

\section{Center Staff}

Most common titles for employees in centers (other than the director) include tenured faculty, faculty on tenure track, faculty on non-tenure track, non-tenured faculty plus courtesy appointment, academic administrative, professional classified, consultant, lecturer, administrative assistant, graduate assistant, clerical/secretarial. Technical staff were included if centers were combined with media/technology production services. See Figure 17.2 for salary levels reported for a total of 92 individuals. Of these, 90 had fiscal-year appointments, while 17.2 had academic-year appointments.

Staff promotion mechanisms vary: 10 centers $(30.3 \%)$ reported no opportunity for promotion; $6(18.2 \%)$ reported merit salary or raises; 3 $(9.1 \%)$ reported changing to administrative titles; $7(21.2 \%)$ said staff

FIGURE 17.2

Salary Ranges for Directors and Staff of Faculty Development Centers

\begin{tabular}{lcc}
\hline Salary Range & No. of Directors & No. of Staff \\
\hline$\$ 80,000-100,000$ & 9.0 & 2 \\
$\$ 70,000-79,999$ & 9.0 & 2 \\
$\$ 60,000-69,999$ & 3.5 & 8 \\
$\$ 50,000-59,999$ & 6.0 & 16 \\
$\$ 40,000-49,999$ & 2.0 & 25 \\
$\$ 30,000-39,999$ & 1.0 & $29^{*}$ \\
$\$ 20,000-29,999$ & 0.0 & 10 \\
Total Reporting & 0.5 & 92 \\
\hline
\end{tabular}

*The only two academic appointments reported were in this salary range. 
could be reclassified; and $7(21.2 \%)$ did not respond to this question. When staff did not hold faculty positions, promotions or raises tended to be determined by the campus personnel office. One campus reported having an academic professional track that paralleled the tenure-track ranks.

\section{Center Functions, Budgets, and Facilities}

All centers that were surveyed engaged in faculty/instructional development; however, many have additional functions. These included instructional technology skills development (19 or $57.6 \%$ ), media production ( 9 or $27.3 \%$ ), examinations services ( 7 or $21.2 \%$ ), grant programs (3 or $9.1 \%$ ), student learning skills ( 2 or $6.1 \%$ ), supplemental instruction learning skills ( 1 or $3 \%$ ), teaching awards (1 or $3 \%$ ), and multicultural teaching and learning services (1 or 3\%). Very little staff time was allocated to basic instructional research ( $a$ range of 0.1-0.6 FTE was reported by 7 centers that did this activity). A greater number of centers ( 20 or $60.1 \%$ ) reported doing some applied instructional development research, with 15 (45.5\%) allocating a range of 0.1-0.5 FTE to such research. Five (15.2\%) of these indicated no time was allocated even though they do it.

Operating budgets for center programs (excluding salaries) varied greatly depending upon, at least in part, whether the budgets included technology/media production or grants programs. Other variables affecting these figures were the size of the institution and the range of services provided. Overall, 7 programs reported budgets over $\$ 300,000$; 6 were in the range of $\$ 150,000-\$ 299,999 ; 4$ were between $\$ 75,000-\$ 149,999 ; 4$ were in the range of $\$ 50,000-\$ 74,999$; 5 were between $\$ 25,000-\$ 49,999$; 6 were below $\$ 24,999$; and one did not report this data. During the past five years, financial resources have increased for $17(51.5 \%)$ of the centers; $8(24.2 \%)$ stayed the same; $6(18.2 \%)$ reported a decrease; and 2 $(6.1 \%)$ did not report.

Travel funds allocated to centers also varied widely and were affected by the number of staff. The allocations in descending amounts were in the ranges of $\$ 15,000-\$ 29,999$ (2 or $6.1 \%), \$ 7,500-\$ 14,999$ (7 or $21.2 \%$ ), $\$ 3,500-\$ 7,499$ (7 or $21.25 \%), \$ 1,500-\$ 3,499$ (12 or $36.3 \%$ ), less than $\$ 1,499(1$ or $3 \%)$, and none (4 or $12.1 \%$ ).

Facilities for most centers include a reception area, director's office, staff office(s), conference room, and resource room. Classrooms and storage rooms are also common. These units tend to be centrally located (17 or $51.5 \%$ ), with $4(12.1 \%)$ located at the edge of campus. While 2 $(6.1 \%)$ had their own buildings, most (17 or $51.5 \%)$ were housed with 
other units or in classroom buildings (4 or $12.1 \%$ ). Five $(15.2 \%)$ were in administration buildings, and $7(21.1 \%)$ were in libraries.

\section{Center Services for Faculty}

All $33(100.0 \%)$ reporting centers provide consultation services. Most indicated that individual consultation included such activities as conferencing, observations, videotaping, gathering student feedback, and providing self-help materials. Consultation to campus groups was a service of $26(78.8 \%)$ of the programs.

Workshops were provided to faculty by both "in-house" and "campus" experts on $32(97.0 \%)$ campuses, while $1(3.0 \%)$ expects to provide workshops in the future. Eighteen centers $(54.5 \%)$ also used external experts for workshops. Other group activities sponsored by centers included general-interest discussion groups on teaching (29 or $87.9 \%$ ); special-interest groups ( 27 or $81.8 \%$ ); breakfast/luncheon groups (20 or $60.6 \%)$; and book groups ( 3 or $9.1 \%$ ).

Another frequently provided service was a newsletter on teaching or faculty development, distributed by $21(63.6 \%)$ centers. Ten centers $(30.3 \%)$ used an assigned editor, while $10(30.3 \%)$ others rotated the responsibility among staff. One campus (3\%) reported using the POD Network's Teaching Excellence as their newsletter.

Resource rooms provided materials for faculty as well as developers on pertinent topics, and $28(84.8 \%)$ centers reported having resource rooms. Some were relatively small while others had extensive collections. Figure 17.3 shows the estimated numbers of materials and usage rates.

Figure 17.3

Estimated Quantity of Resource Room Materials and Usage in Raw Numbers

\begin{tabular}{lcc}
\hline Material & Range & Mode \\
\hline Book titles & $10-2000$ & 100 \\
Subscriptions & $5-25$ & 10 \\
Videotapes & $10-141$ & 20 \\
Self-instructional material & $10-4000$ & 10 \\
CD-ROMs & 8 & 1 \\
Usages/year & $20-200$ & no mode \\
\hline
\end{tabular}




\section{Awards and Grants for Faculty}

Centers engage in the selection process for campus teaching awards on 17 campuses (51.5\%): $12(36.4 \%)$ reported that they supervise or assist in the development of criteria for these awards; 13 (39.4\%) review award nominations; $10(30.3 \%)$ sponsor recognition of the awardees; and three $(9.1 \%)$ prepare external award nominations.

Grant programs are administered by centers on $17(51.5 \%)$ campuses. The range of funds for small grants for teaching development were as follows: $\$ 150,000-\$ 299,999$ (1); $\$ 50,000-\$ 149,999$ (2); $\$ 25,000-\$ 49,999$ (4); $\$ 10,000-\$ 24,999$; (9); less than $\$ 5,000$ (1). Requests for proposals were issued once a year (9); 2-3 times per year (7); accepted any time (6).

\section{Center Services for Graduate Teaching Assistants}

Centers on $27(81.8 \%)$ campuses offer individual consultation for graduate teaching assistants (GTAs) similar to those offered to faculty. In addition, 3 campuses provide mentoring services. Most respondents $(28$ or $84.8 \%$ ) also consult with departments on GTA programs, and $13(39.4 \%)$ offer training for departmental GTA supervisors.

Organized, campus-wide programs for GTAs are provided by 28 campuses $(84.8 \%)$. These are taught by center staff, campus faculty, administrators, and other GTAs. Frequency of programs vary, with 18 campuses (54.5\%) holding them annually; 14 (42.4\%) holding them each semester; $4(12.1 \%)$ holding them each quarter; and $1(3 \%)$ holding them monthly. Collaboration with other units to provide GTA workshops was reported by 12 centers (36.4\%). Collaborators included the English as a Second Language (ESL) program ( 10 or $30.3 \%$ ), the graduate college ( 9 or $27.3 \%$ ), international affairs (5 or $15.2 \%)$, the library ( 2 or $6.1 \%)$, and 1 $(3.0 \%)$ each with the writing center, judicial affairs, computing, the higher education center, the center for women, the College of Arts and Sciences, the provost, instructional technology, freshman seminar, and academic departments.

Twenty-six centers $(\mathbf{7 8 . 8 \%})$ provide materials for GTA training. These include teaching handouts ( 24 or $72.7 \%$ ); teaching handbooks (21 or $63.6 \%$ ); videotapes (19 or $57.6 \%$ ); and published books (12 or $36.4 \%$ ).

Courses on college teaching are taught by 17 centers $(51.5 \%): 6$ $(18.2 \%)$ teach them once a year, while $3(9.1 \%)$ provide them each term, and $3(9.1 \%)$ provide them $2-4$ times per year. One center $(3 \%)$ even teaches these courses 5 or more times per year. The least frequent was a center that taught the course every 2-5 years. 
International Teaching Assistants

Special needs of international graduate teaching assistants (ITAs) are served by 12 centers $(36.4 \%) ; 18$ campuses $(54.5 \%)$ report that ITAs are taught elsewhere. Topics include: English as a second language, inter-cultural communications, videotaped microteaching, and individual consultation.

Collaborators in ITA workshops included the ESL program $(9$ or $27.3 \%$ ), the graduate college (6 or 18.2\%), and international affairs ( 7 or $21.2 \%)$. The average number of ITA participants in each workshop is: 1024 ITAs ( 5 or $15.2 \%$ ); $25-40$ (6 or $18.2 \%) ; 41-60$ (6 or $18.2 \%)$; and 60 (4 or $12.1 \%$ ). The largest number reported was 400 for the fall term.

Handouts provided to ITAs by 18 centers included in-house workbooks and materials ( 15 or $45.5 \%$ ) or published books and workbooks (4 or $12.1 \%)$. Only 3 centers $(9.1 \%)$ had representative ITA advisory groups that assist in designing the programs.

Classroom consultation is provided for ITAs during their teaching assignments by 17 centers $(51.5 \%)$. Fourteen centers $(42.4 \%)$ respond to requests, $3(9.1 \%)$ routinely observe all ITAs, and $1(3 \%)$ observes for science and engineering ITAs only.

\section{Evaluation and Assessment Services}

Instructionally related evaluation and assessment work occurs in some centers in several ways. Consultation on student evaluation of teaching instruments was reported by 22 centers $(66.7 \%)$, while only $5(15.2 \%)$ actually manage student evaluation of the teaching process. In addition, 8 centers $(24.2 \%)$ provide computerized examination services including examination scoring, test analysis statistics, consultation on test construction, scoring of student evaluations of teaching, and scoring surveys or questionnaires.

At 11 institutions (33.3\%), centers are involved in activities to assess learning outcomes in the following ways: individual consultation (11 or $33.3 \%$ ), serving on committees (10 or $30.3 \%$ ), providing materials (9 or $27.3 \%$ ), consulting with departments on ways to assess learning ( 8 or $24.2 \%$ ), synthesizing literature ( 7 or $21.2 \%$ ), providing workshops (6 or $18.2 \%)$, and managing programs of outcomes assessment ( 2 or $6.1 \%)$.

\section{Technology and Distance Learning Services}

Respondents from 27 centers $(81.8 \%)$ indicate that they support instructional technology (IT) development in a variety ways, including IT application workshops (23 or $69.7 \%$ ), individual consultations on IT (18 or 
$54.5 \%$ ), workshops on distance learning (17 or $51.5 \%$ ), consultations with distance learning units (15 or $45.5 \%)$, consultations with departments on IT (14 or $42.2 \%$ ), software workshops (14 or $42.2 \%$ ), technical instruction on software ( 8 or $24.2 \%)$, technical equipment assistance (7 or $21.2 \%)$, serving on a local Teaching, Learning, and Technology Roundtable (TLTR) (7 or $21.2 \%$ ), or sponsoring a local TLTR (5 or $15.2 \%$ ).

\section{Directions in the Next Five Years}

When asked what new initiatives centers expected to pursue in the next five years, the most frequent response involved increasing services related to instructional technology (7 or $21.2 \%$ ) or the enhancement of graduate student programs (7 or 21.2\%). Other directions mentioned more than once were assessment services ( 3 or $9.1 \%$ ), peer review ( 3 or $9.1 \%$ ), and preparing future faculty or a formal professional development program ( 3 or $9.1 \%$ ). The following responses occurred only once: grants, research, classroom research support, pre-tenure support, posttenure review support, diversity, examinations services, book groups, departmental chair program, center staff enhancement, and center facilities improvement.

\section{IMPICATIONS FOR THE POD NETWORK}

1) Professional Staff Development. This study raises significant concerns about professional development opportunities for, and the appointment of, staff at teaching centers. Directors of centers come from a variety of backgrounds, some tenured and some not, but generally they were identified in some way as faculty or academic-administrative appointments. On the other hand, staff members of centers are not necessarily faculty and are occasionally hired through the personnel offices as "professional staff." Inconsistencies in selection processes, promotion issues, merit salary increases, evaluation of performance, and collegial status of faculty members are issues that the professional association should at least examine. Such examination could lead to recommendations that would ensure some support for non-traditional academics who are interested in improving their career status on campus. The inconsistencies in appointments of faculty development staff members may simply reflect the local culture of the campus, but they merit consideration by the field.

2) Travel. The limitations on travel budget funds also should be a consideration for the POD Network in planning costs associated with its 
annual conference. The amount of money allocated to a center's travel fund may range from $\$ 1,500-\$ 3,500$, allowing only one to four trips per center per year.

3) Center Directors. It is worth noting that almost half of all center directors have been in their positions for five years or less. This may indicate a professional development need that the POD Network could respond to by offering additional programs designed for new center directors.

4) Growtb in the Future. Future directions identified by many centers include instructional technology or graduate student development programs. Secondary directions include learning outcomes assessment and peer review. These are areas that the POD Network members may be interested in as future conference topics.

5) Diversity. Finally, it is interesting to note that only one center reported diversity as a future area of new development. It would be useful to consider why this issue has been identified by a great many institutional missions but is not cited as a growth area for many programs. It may be that centers currently address diversity and, therefore, do not define this as a new direction. It may also be that other units on campus address diversity issues, in which case members of the POD Network may want to consider the role faculty/instructional developers might play in collaborating with these units. Additionally, if the need for mentoring diverse faculty is currently being addressed at some institutions, POD members may be interested in exploring the methods being used in such programs.

\section{References}

Centra, J. A. (1976). Faculty development practices in US colleges and universities. Project Report, 76-30. Princeton, NJ: Educational Testing Service.

Chambers, J. (1998). Teaching and learning centers in US bigher education: Current and projected roles and services. Unpublished report, Florida Community College, Jacksonville.

Crawley, A. L. (1995). Faculty development programs at research universities: Implications for senior faculty renewal. To Improve the Academy, 14, 65-90.

Erickson, G. (1986). A survey of faculty development practices. To Improve the Academy, 5, 182-196.

Gullatt, D. E., \& Weaver, S. W. (1997, October). Use offaculty development activities to improve the effectiveness of US institutions of higher education. Paper presented 
at the meeting of the Professional and Organizational Development Network in Higher Education, Hines City, FL.

Contact:

Delivee L. Wright

121 Benton Hall

University of Nebraska, Lincoln

Lincoln, NE 68588-0623

(402) $472-3079$

(402) 472-4932 (FAX)

dwright@unlinfo.unl.edu

Delivee L. Wright is Director of the Teaching and Learning Center and Associate Professor of Educational Administration at the University of Nebraska, Lincoln. She has worked in faculty development for 31 years and with the TLC for 25 years and taught a graduate seminar in college teaching. She has received a Kudo Award from the University of Nebraska Board of Regents for meritorious service and dedication to improving the quality of the university. She served as "Co-Executive Director" (President) of the POD Network in 1989-1991, was on the CORE Committee for 7 years, and has served on numerous committees. She is a frequent contributor to POD programs. 


\section{APPENDIX 17.1 \\ INSTITUTIONS PARTICIPATING IN THIS SURVEY}

Brigham Young University

Carnegie Mellon University

Case Western University

George Washington University

Indiana University

Kansas State University

Massachusetts Institute of Technology

Stanford University

Temple University

Texas Tech University

The Ohio State University

The University of Texas at Austin

University of Arkansas

University of California, Berkeley, GSI Teaching Resource Center

University of California, Berkeley, Educational Development

University of California, Davis

University of California, Los Angeles

University of California, Santa Cruz

University of Colorado, Boulder, Graduate Teacher Program

University of Delaware

University of Georgia

University of Illinois, Champaign-Urbana

University of Iowa

University of Kentucky

University of Massachusetts, Amherst

University of Michigan

Virginia Polytechnic Institute and State University

University of Nebraska, Lincoln

University of North Carolina, Chapel Hill

University of Oklahoma

University of Rhode Island

University of Wyoming

Vanderbilt University 